\title{
Effects of Delayed Cord Clamping on Intraventricular Hemorrhage in Preterm Infants
}

\author{
Mobina Varij Kazemi, ${ }^{1}$ Zahra Akbarianrad, ${ }^{1}$ Yadolla Zahedpasha, ${ }^{1}$ Raheleh Mehraein, ${ }^{2}$ and Mohsen \\ Haghshenas Mojaveri ${ }^{1, *}$ \\ ${ }^{1}$ Non-Communicable Pediatric Diseases Research Center, Health Research Institute, Babol University of Medical Sciences, Babol, Iran \\ ${ }^{2}$ Department of Radiology, Babol University of Medical Sciences, Babol, Iran \\ "Corresponding author: Mohsen Haghshenas Mojaveri, Non-Communicable Pediatric Diseases Research Center, Health Research Institute, Babol University of Medical \\ Sciences, Babol, Iran. Tel: +98-9113233151, E-mail: matia.mojaveri@yahoo.com
}

Received 2016 April 28; Revised 2016 June 08; Accepted 2017 July 18.

\begin{abstract}
Background: One of the benefits of delayed cord clamping is a reduction in the rate of intraventricular hemorrhage. The findings in this regard are controversial and some negative effects of the procedure have been reported.

Objectives: The purpose of this study was to investigate the effects of delayed cord clamping on intraventricular hemorrhage in preterm infants.

Methods: This clinical trial was carried out on 70 preterm neonates delivered via cesarean section. Their gestational age was less than 32 weeks and the birth weight less than 1500 grams. Neonates were randomly assigned to two groups of early cord clamping (less than 10 seconds) or delayed clamping of the umbilical cord (30 - 45 seconds after birth). 3 to 7 days after birth, presence of Intraventricular hemorrhage (IVH) in both groups was checked by ultrasonography (Mindray machine, model m7) and. Rate and severity of IVH was compared between the two groups.

Results: There was no significant difference in mean gestational age, birth weight, gender distribution and medications in both groups of delayed cord clamping and early clamping of the umbilical cord. The incidence of seizures in the early clamping was $8.6 \%$ and in the delayed clamping zero $(\mathrm{P}=0.239)$. The incidence rate of IVH and periventricular leukomalacia $(\mathrm{PVL}) \mathrm{was} 11.43 \%$ and $5.7 \%$, respectively in the early clamping, while this rate was zero in the delayed clamping group. This difference was not statistically significant in both indicators ( $\mathrm{P}=0.12$ and $\mathrm{P}=0.493$, respectively).

Conclusions: The results showed that intraventricular hemorrhage in premature neonates with delayed clamping was less prevalent than those with early clamping, and may be used as a reliable method.

Keywords: Delayed Cord Clamping, Intraventricular Hemorrhage, Preterm Neonates
\end{abstract}

\section{Background}

Survival rate of preterm infants has increased in recent decades. This has been associated with the growing importance of diseases in preterm infants. The risk of brain damage in these infants is of particular importance. Despite many advances in providing services to these infants, brain damages following hemorrhage in germinal matrix and Intraventricular Hemorrhage(IVH) are particularly critical due to their long-term neurological effects. The incidence of IVH in preterm infants with gestational age less than 32 weeks, and weighing less than 1500 grams (very low birth weight,VLBW) is between 20 and 25\%. Various methods have been proposed to prevent IVH, including the use of indomethacin prophylaxis and skillful use of antenatal corticosteroids before birth and surfactant after birth in preterm infants with respiratory distress syndrome (1).

Cord clamping in preterm infants, due to lower volume of blood, has hemodynamic effects (2). This affects the incidence rate of complications such as anemia, intraventricular hemorrhage(IVH), need for blood transfusion, and need for phototherapy and intestinal necrosis (3-7). IVH is a major complication that its incidence rate has been reported to be reduced by delayed cord clamping (8). On the other hand, some reports have shown the increased incidence of IVH in delayed cord clamping (9). The protective effects of delayed cord clamping in movement disorders, especially in male newborns, are among its long-term effects (10). In some studies, no difference in the incidence of IVH has been reported using the two methods (7).

Due to the small amount of blood in preterm infants' system, according to a theory, the higher need for blood transfusion in infants which is reduced by delaying the clamping of the umbilical cord for 30 - 60 seconds, increases incidence of IVH. However, this theory has been rejected by some authors, who have not found any relationship between hematocrit, the need for blood transfusion 
and the extent of IVH (11).

More studies are needed in this area considering the inconsistencies in the findings of different studies on the reduced incidence of IVH, the lack of evidence for decisionmaking in this regards, and ease and low cost of this method and its promising effects on reducing the incidence of IVH.

\section{Objectives}

The purpose of this study was to investigate the effects of delayed cord clamping on intraventricular hemorrhage in preterm infants.

\section{Methods}

This clinical trial was conducted on preterm infants born by C-section in Rohani hospital in Babol, Northern Iran, during 2014 - 2015. Inclusion criteria were preterm infants with gestational age of less than 32 weeks, weighing less than 1500 grams at birth, born by C-section who did not require advanced resuscitation and showed no congenital anomaly in physical examination. Exclusion criteria included maternal use of medications affecting the coagulation system, birth asphyxia, need for resuscitation at the time of delayed clamping, birth trauma, need for advanced resuscitation, infants from multiple gestation or breech presentation as the cause of C-section, and mother's systemic diseases such as preeclampsia, hypertension, and uncontrolled diabetes. The study was registered in the registry of clinical trials under the code IRCT2014091319145N1 and was approved by the ethics committee of Babol University of Medical Sciences (Code 4709). The number of samples was considered two groups of 35 based on the similar studies. Eligible preterm infants were randomly assigned to two groups of immediate or delayed cord clamping. In the immediate clamping group, the umbilical cord was clamped immediately in less than $10 \mathrm{sec}-$ onds, while in another group, the umbilical cord clamping was delayed by 30 - 45 seconds. In the delayed cord clamping group, during the 30 - 45-seconds delay in clamping the umbilical cord, the infants were put under sterile conditions 25 - $30 \mathrm{~cm}$ below the mother, before umbilical cord was clamped. During hospitalization in days $3-7$, all infants were routinely examined using ultrasound to check for the presence and severity of anterior IVH. All ultrasounds were done by a sonographer using a MINDRY M7 device. Mothers' and infants'clinical findings were recorded by a clinician, and the ultrasound findings including the presence or absence of severe IVH, were entered in a check list by the sonographer. The data was analyzed using SPSS
V. 20 and t-test, chi-square test and Fisher's exact test. $\mathrm{P}<$ 0.05 was considered as the significance level.

\section{Results}

The study was conducted on 70 preterm infants in two groups of 35 infants (delayed and immediate cord clamping groups). Mean age and weight as well as infants' gender distribution and history of maternal medication of the subjects in both groups showed no significant difference (Tables 1 and 2). As shown in Table 3, distribution of IVH, seizures, periventricular leukomalacia (PVL) and its grade of severity were different in the two groups, although with no statistically stsignificant difference; however, the distributions of outcome in the two groups of delayed and immediate clamping were significantly different.

\section{Discussion}

This study aimed to determine the effects of delayed cord clamping on reducing the incidence rate of IVH in preterm infants and was conducted on 70 preterm infants (35 in the delayed cord clamping group and 35 in the immediate cord clamping group). PVL and IVH were observed in $5.7 \%$ and $11.43 \%$ of the infants in the immediate cord clamping group, while no PVL or IVH were observed in the delayed cord clamping group. However, the difference was not statistically significant. Regarding the demographic parameters such as gender distribution and history of medication, there was no significant difference between the two groups. In a review study, Raju et al. (2012) .reported that delayed cord clamping in preterm infants is associated with benefits such as a $50 \%$ reduction in the incidence rate of IVH, while in term infants, a 60-second delay in cord clamping is associated with improved blood flow and RBC volume and reduced need for blood transfusion (5). Mercer et al. (2006) examined 72 preterm infants in a randomized controlled clinical trial. In that study, 2 cases of IVH among 23 boys in the delayed group was reported versus 8 cases of IVH among 19 boys in the immediate clamping group (6). Hofmeyr et al. (1993) reported the incidence of IVH as $20 \%$ and $24 \%$ in the delayed group and in the immediate group, respectively, without any significant difference. In that study, the delay in cord clamping was 60 - 120 seconds (4). In another study by Hofmeyr et al. (1988) on 38 preterm infants, the incidence of IVH in the delayed cord clamping group and immediate cord clamping group was reported as 35\% and $77 \%$, respectively, which is in agreement with the findings of the presents study. However, in a study by Chiruvolu et al. (2015) to examine the effect of delayed cord clamping on the incidence 
Table 1. Distribution of Mean Gestational Age and Birth Weight in the Two Groups of Delayed Cord Clamping and Immediate Cord Clamping

\begin{tabular}{l|c|c|c}
\hline \multirow{2}{*}{ Parameter } & Group & No. & Mean \pm SD \\
\hline \multirow{2}{*}{ Gestational age, week } & Immediate cord clamping & 35 & $29.8 \pm 1.8$ \\
\cline { 2 - 4 } & Delayed cord clamping & 35 & $30.1 \pm 1.7$ \\
\hline \multirow{2}{*}{ Birth weight, $\mathbf{n}$} & Immediate cord clamping & 35 & $1241.2 \pm 233.7$ \\
\cline { 2 - 4 } & Delayed cord clamping & 35 & $1260.8 \pm 213.4$ \\
\hline
\end{tabular}

Table 2. Distribution of Gender and History of Medication Use in the Infants of Two Groups of Delayed Cord Clamping and Immediate Cord Clamping ${ }^{\mathrm{a}}$

\begin{tabular}{cccc}
\hline Parameter & $\begin{array}{c}\text { Immediate Cord } \\
\text { Clamping }\end{array}$ & $\begin{array}{c}\text { Delayed Cord } \\
\text { Clamping }\end{array}$ & P Value \\
\hline Gender & $18(51.4)$ & $17(48.6)$ & 1 \\
\hline Female & $17(48.6)$ & $18(51.4)$ & 1 \\
\hline Male & & & \\
Mternal \\
medication use
\end{tabular}

${ }^{\text {a }}$ Values are expressed as No. (\%).

of IVH in preterm infants with gestational age less than 32 weeks, 60 infants were studied in the delayed clamping group and 88 were studied in the immediate clamping group. Gestational age and birth weight were similar in the two groups. No significant difference was found in the Apgar score between the two groups. The incidence rate of IVH in the delayed clamping group was $18.3 \%$, while it was $35.2 \%$ in the immediate clamping group. The difference was statistically significant (12). In this respect, the incidence of IVH in the delayed clamping group was similar to our study. The lack of significant relationship in the present study may be due to the small sample size. Unlike the results of the present study and the studies mentioned above, after studying preterm infants in two groups of delayed clamping (30 - 45 seconds) and immediate (less than 10 seconds), Oh et al. (2011) reported higher hematocrit levels, need for blood transfusion, intestinal necrosis and reduced sepsis in the delayed clamping group. In this study, the incidence of IVH in the delayed group was reported to be higher than in the immediate group (9), which may be due to lack of control of confounding variables. However, studies suggest beneficial effects of delayed clamping compared to immediate clamping in preterm infants although differences are significant in some cases and insignificant in some other (5). In a study on infants with gestational age less than 36 weeks in two groups of immediate and
Table 3. Distribution of Seizure, IVH, PVL, Grade, and Outcome in the Infants of the Two Groups of Delayed and Immediate Cord Clamping ${ }^{\mathrm{a}}$

\begin{tabular}{|c|c|c|c|}
\hline Parameter & $\begin{array}{l}\text { Immediate Cord } \\
\text { Clamping }\end{array}$ & $\begin{array}{l}\text { Delayed Cord } \\
\text { Clamping }\end{array}$ & P Value \\
\hline Seizure & & & 0.239 \\
\hline No & $32(91.4)$ & $35(100)$ & \\
\hline Yes & $3(8.6)$ & - & \\
\hline IVH & & & 0.12 \\
\hline No & $31(88.57)$ & $35(100)$ & \\
\hline Yes & $4(11.43)$ & - & \\
\hline PVL & & & 0.493 \\
\hline No & $33(94.3)$ & $35(100)$ & \\
\hline Yes & $2(5.7)$ & - & \\
\hline Grade & & & 0.12 \\
\hline 0 & $31(88.57)$ & $35(100)$ & \\
\hline 1 & $1(2.83)$ & - & \\
\hline 2 & $3(8.6)$ & - & \\
\hline Outcome & & & 0.003 \\
\hline $\begin{array}{l}\text { No- } \\
\text { complication }\end{array}$ & $26(74.28)$ & $35(100)$ & \\
\hline $\begin{array}{l}\text { Complica- } \\
\text { tions }\end{array}$ & $9(25.72)$ & - & \\
\hline
\end{tabular}

${ }^{\mathrm{a}}$ Values are expressed as No. (\%).

delayed clamping, Strauss et al. (2008) reported a significant increase in circulating $\mathrm{RBC}$ volume/mass $(\mathrm{P}=0.04)$ and weekly hematocrit $(\mathrm{P}<0.005)$. In that study, the need for mechanical ventilation did not differ between the two groups, and the need for phototherapy was higher in the delayed group (7).

No case of seizure was observed in the delayed clamping group. A frequency of $8.6 \%$ was observed in the immediate clamping group; however, the difference was not significant. The outcome was significantly different between the two groups. In a study by Chiruvolu et al. (2015) to examine the effect of delayed cord clamping on the incidence of IVH in preterm infants with gestational age less than 32 weeks, the rate of morbidity or mortality was not 
significantly different between the two groups (12). Sommers et al. (2012) investigated the hemodynamic effects of delayed and immediate cord clamping in preterm infants in a randomized controlled clinical trial. Beneficial effects on cardiac function and blood flow in the superior vena cava were reported. In general, delayed cord clamping in preterm infants improved their hemodynamic status in the first days after birth (2). In a seven-month followup of immediate and delayed clamping groups, Mercer et al. (2010) reported only the protective effects against male preterm infants' movement disorders $(10,13)$. The above results are in line with the results of this study and suggest that this method is safe and without complications. Thus, considering the results of this study, a more extensive study with a larger sample size is recommended in this regard. With respect to preterm infants, delayed cord clamping should be used in the case of absence of contraindications.

\subsection{Conclusion}

Our Study showed a lower incidence rate of IVH in preterm infants in the delayed clamping group compared to the immediate clamping group so that no case of IVH was observed in the delayed clamping group. Although the difference was not statistically significant, given the lack of significant relationship in terms of morbidity and mortality, it can be said that this method can be used as a safe method although more extensive studies with larger sample size are needed to demonstrate the real effects of the method.

\section{Acknowledgments}

The authors thank the staff of delivery and operating rooms and all mothers of the neonates for helping us in this study and we thanks Clinical Research Development Unit of Rouhsni Hospital.

\section{References}

1. Carlo WA, Ambalavanan N. Kliegman, tanton, Stgem, Schor, Nelson Textbook of Pediatrics. 20th ed. Elsevier; 2016. p. 835.Nervous System Disorders.
2. Sommers R, Stonestreet BS, Oh W, Laptook A, Yanowitz TD, Raker C, et al. Hemodynamic effects of delayed cord clamping in premature infants. Pediatrics. 2012;129(3):e667-72. doi: 10.1542/peds.2011-2550. [PubMed: 22331336].

3. Hofmeyr GJ, Bolton KD, Bowen DC, Govan JJ. Periventricular/intraventricular haemorrhage and umbilical cord clamping. Findings and hypothesis. S Afr Med J. 1988;73(2):104-6. [PubMed: 3340910].

4. Hofmeyr GJ, Gobetz L, Bex PJ, Van der Griendt M, Nikodem C, Skapinker R, et al. Periventricular/intraventricular hemorrhage following early and delayed umbilical cord clamping. A randomized controlled trial. Online J Curr Clin Trials. 1993;Doc No 110:[2002 words. [PubMed: 8305996] 26 paragraphs].

5. Raju TN, Singhal N. Optimal timing for clamping the umbilical cord after birth. Clin Perinatol. 2012;39(4):889-900. doi: 10.1016/j.clp.2012.09.006. [PubMed: 23164185].

6. Mercer JS, Vohr BR, McGrath MM, Padbury JF, Wallach M, Oh W. Delayed cord clamping in very preterm infants reduces the incidence of intraventricular hemorrhage and late-onset sepsis: a randomized, controlled trial. Pediatrics. 2006;117(4):1235-42. doi: 10.1542/peds.2005-1706. [PubMed: 16585320].

7. Strauss RG, Mock DM, Johnson KJ, Cress GA, Burmeister LF, Zimmerman $\mathrm{MB}$, et al. A randomized clinical trial comparing immediate versus delayed clamping of the umbilical cord in preterm infants: shortterm clinical and laboratory endpoints. Transfusion. 2008;48(4):65865. doi: 10.1111/j.1537-2995.2007.01589.x. [PubMed: 18194383].

8. Schmid MB, Reister F, Mayer B, Hopfner RJ, Fuchs H, Hummler HD. Prospective risk factor monitoring reduces intracranial hemorrhage rates in preterm infants. Dtsch Arztebl Int. 2013;110(29-30):489-96. doi: 10.3238/arztebl.2013.0489. [PubMed: 24000297].

9. Oh W, Fanaroff AA, Carlo WA, Donovan EF, McDonald SA, Poole WK, et al. Effects of delayed cord clamping in very-low-birth-weight infants. J Perinatol. 2011;31 Suppl 1:S68-71. doi: 10.1038/jp.2010.186. [PubMed: 21448208].

10. Mercer JS, Vohr BR, Erickson-Owens DA, Padbury JF, Oh W. Sevenmonth developmental outcomes of very low birth weight infants enrolled in a randomized controlled trial of delayed versus immediate cord clamping. J Perinatol. 2010;30(1):11-6. doi: 10.1038/jp.2009.170. [PubMed: 19847185].

11. Valieva OA, Strandjord TP, Mayock DE, Juul SE. Effects of transfusions in extremely low birth weight infants: a retrospective study. J Pediatr. 2009;155(3):331-37 e1. doi: 10.1016/j.jpeds.2009.02.026. [PubMed: 19732577].

12. Chiruvolu A, Tolia VN, Qin H, Stone GL, Rich D, Conant RJ, et al. Effect of delayed cord clamping on very preterm infants. Am J Obstet Gynecol. 2015;213(5):676 e1-7. doi:10.1016/j.ajog.2015.07.016. [PubMed: 26196456].

13. Radic JA, Vincer M, McNeely PD. Temporal trends of intraventricular hemorrhage of prematurity in Nova Scotia from 1993 to 2012. J Neurosurg Pediatr. 2015;15(6):573-9. doi: 10.3171/2014.11.PEDS14363. [PubMed: 26030328]. 